\title{
INTEGRAL INEQUALITIES OF GRONWALL TYPE FOR PIECEWISE CONTINUOUS FUNCTIONS
}

\author{
DRUMI D. BAINOV \\ Medical University of Sofia \\ P.O. Box 45 \\ 1504 Sofia, Bulgaria \\ SNEZHANA G. HRISTOVA \\ Plovdiv University "Paissii Hilendarski" \\ Tsar Asen Str., 24, 4000 Plovdiv, Bulgaria
}

(Received March, 1995; Revised March, 1996)

In this paper we generalize the integral inequality of Gronwall and study the continuous dependence of the solution of the initial value problem for nonlinear impulsive integro-differential equations of Volterra type on the initial conditions.

Key words: Integral Inequalities, Piecewise Continuous Functions.

AMS subject classifications: 26D10.

\section{Introduction}

In the present paper analogues of Gronwall's inequality for piecewise continuous functions are introduced. The results obtained for these inequalities are applied to finding sufficient conditions for continuous dependence on the initial conditions of the solutions of the initial value problem for nonlinear impulsive integro-differential equations.

The integral inequalities, established in this paper, can successfully be used in the qualitative theory of the impulsive differential equations.

Let us note that the present paper generalizes some results obtained in [2-4].

\section{Basic Notations. Auxiliary Assertions}

Let $0 \leq t_{0}<t_{1}<t_{2}<\ldots$ and $\lim _{k \rightarrow \infty} t_{k}=\infty$.

Denote by $P C\left(\left[t_{0}, \infty\right), \mathbb{R}_{+}\right)$the set of all functions $u:\left[t_{0}, \infty\right) \rightarrow \mathbb{R}_{+}$, which are piecewise continuous with discontinuity of the first kind at the points $t_{k}(k \in \mathbb{N})$, $u\left(t_{k}+0\right)-u\left(t_{k}-0\right)<\infty$ and $u\left(t_{k}\right)=u\left(t_{k}-0\right)$.

Lemma 1: (Theorem 16.4, [1]) Let for $t \geq t_{0}$ the inequality 


$$
u(t) \leq a(t)+\int_{t_{0}}^{t} g(t, s) u(s) d s+\sum_{t_{0}<t_{k}<t} \beta_{k}(t) u\left(t_{k}\right),
$$

hold, where $\beta_{k}(t) \quad(k \in \mathbb{N})$ are nondecreasing functions for $t \geq t_{0}, a \in$ $P C\left(\left[t_{0}, \infty\right), \mathbb{R}_{+}\right)$is a nondecreasing function, $u \in P C\left(\left[t_{0}, \infty\right), \mathbb{R}_{+}\right)$, and $g(t, s)$ is a continuous nonnegative function for $t, s \geq t_{0}$ and nondecreasing with respect to $t$ for any fixed $s \geq t_{0}$.

Then, for $t \geq t_{0}$ the following inequality is valid:

$$
u(t) \leq a(t) \prod_{t_{0}<t_{k}<t}\left(1+\beta_{k}(t)\right) \exp \left(\int_{t_{0}}^{t} g(t, s) d s\right)
$$

\section{Main Results}

Theorem 1: Let for $t \geq t_{0}$ the inequality

$$
\begin{gathered}
u(t) \leq a(t)+\int_{t_{0}}^{t} b(s) u(s) d s+\int_{t_{0}}^{t}\left(\int_{t_{0}}^{s} k(s, \tau) u(\tau) d \tau\right) d s \\
+\int_{t_{0}}^{t}\left(\int_{t_{0}}^{s}\left(\int_{t_{0}}^{\tau} h(s, \tau, \sigma) u(\sigma) d \sigma\right) d \tau\right) d s+\sum_{\substack{t_{0}<t_{k}<t \\
k}} \beta_{k} u\left(t_{k}\right)
\end{gathered}
$$

hold, where $a, u \in P C\left(\left[t_{0}, \infty\right), \mathbb{R}_{+}\right), a$ is nondecreasing, $b \in C\left(\left[t_{0}, \infty\right), \mathbb{R}_{+}\right), k(t, s)$ and $h(t, s, \tau)$ are continuous and nonnegative functions for $t, s, \tau \geq t_{0}$ and $\beta_{k} \geq 0$ $(k \in \mathbb{N})$ are constants.

Then, the following inequality is valid:

$$
\begin{gathered}
u(t) \leq a(t) \prod_{t_{0}<t_{k}<t}\left(1+\beta_{k}\right) \exp \left(\int_{t_{0}}^{t} b(s) d s+\int_{t_{0}}^{t} \int_{t_{0}}^{s} k(s, \tau) d \tau d s\right. \\
\left.+\int_{t_{0}}^{t} \int_{t_{0}}^{s} \int_{t_{0}}^{s} h(s, \tau, \sigma) d \sigma d \tau d s\right)
\end{gathered}
$$

Proof: Denote the right-hand side of inequality (3) by $v(t)$. The function $v \in$ $P C\left(\left[t_{0}, \infty\right), \mathbb{R}_{+}\right)$is nondecreasing, $v\left(t_{0}\right)=a\left(t_{0}\right), u(t) \leq v(t)$ for $t \geq t_{0}$ and it satisfies the inequality

$$
\begin{gathered}
v(t) \leq a(t)+\int_{t_{0}}^{t}\left[b(s)+\int_{t_{0}}^{s} k(s, \tau) d \tau+\int_{t_{0}}^{s} \int_{t_{0}}^{\tau} h(s, \tau, \sigma) d \sigma d \tau\right] v(s) d s \\
+\sum_{t_{0}<t_{k}<t} \beta_{k} v\left(t_{k}\right) .
\end{gathered}
$$

We apply Lemma 1 to inequality (5) for

$$
g(t, s) \equiv b(s)+\int_{t_{0}}^{s} k(s, \tau) d \tau+\int_{t_{0}}^{s} \int_{t_{0}}^{\tau} h(s, \tau, \sigma) d \sigma d \tau, \beta_{k}(t) \equiv \beta_{k}
$$


and obtain inequality (4).

Theorem 2: Let for $t \geq t_{0}$ the following inequality hold

$$
\begin{gathered}
u(t) \leq a(t)+\int_{t_{0}}^{t} b(t, s) u(s) d s+\int_{t_{0}}^{t}\left(\int_{t_{0}}^{s} k(t, s, \tau) u(\tau) d \tau\right) d s \\
\quad+\sum_{t_{0}<t_{k}<t} \beta_{k}(t) u\left(t_{k}\right),
\end{gathered}
$$

where $u, a \in P C\left(\left[t_{0}, \infty\right), \mathbb{R}_{+}\right)$, $a$ is nondecreasing, $b(t, s)$ and $k(t, s, \tau)$ are continuous and nonnegative functions for $t, s, \tau \geq t_{0}$ and are nondecreasing with respect to $t$, $\beta_{k}(t) \quad(k \in \mathbb{N})$ are nondecreasing for $t \geq t_{0}$.

Then, for $t \geq t_{0}$, the following inequality is valid:

$$
u(t) \leq a(t) \prod_{t_{0}<t_{k}<t}\left(1+\beta_{k}(t)\right) \exp \left(\int_{t_{0}}^{t} b(t, s) d s+\int_{t_{0}}^{t} \int_{t_{0}}^{s} k(t, s, \tau) d \tau d s\right)
$$

Proof: Denote the right-hand side of inequality (6) by $v(t)$. The function $v \in$ $P C\left(\left[t_{0}, \infty\right), \mathbb{R}_{+}\right)$is nondecreasing, $u(t) \leq v(t)$ and

$$
v(t) \leq a(t)+\int_{t_{0}}^{t}\left[b(t, s)+\int_{t_{0}}^{s} k(t, s, \tau) d \tau\right] v(s) d s+\sum_{t_{0}<t_{k}<t} \beta_{k}(t) v\left(t_{k}\right) .
$$

We apply Lemma 1 to inequality (8) and obtain inequality (7).

Theorem 3: Let for $t \geq t_{0}$ the following inequality hold

$$
u(t) \leq a(t)+\int_{t_{0}}^{t} b(s)\left[u(s)+\int_{t_{0}}^{s} k(\tau) u(\tau) d \tau\right] d s+\sum_{t_{0}<t_{k}<t} \beta_{k} u\left(t_{k}\right)
$$

where $u, \quad a \in P C\left(\left[t_{0}, \infty\right), \mathbb{R}_{+}\right), \quad a$ is nondecreasing, $b, \quad k \in C\left(\left[t_{0}, \infty\right), \mathbb{R}_{+}\right), \quad \beta_{k} \geq 0$ $(k \in \mathbb{N})$ are constants.

Then, for $t \geq t_{0}$, the following inequality is valid:

$$
\begin{aligned}
u(t) \leq & a(t)+\left\{\int_{t_{0}}^{t} b(s)\left[a(s)+\int_{t_{0}}^{s} k(\tau) a(\tau) d \tau\right] d s+\sum_{t_{0}<t_{k}<t} \beta_{k} a\left(t_{k}\right)\right\} \\
& \times \prod_{t_{0}<t_{k}<t}\left(1+\beta_{k}\right) \exp \left\{\int_{t_{0}}^{t} b(s)\left[1+\int_{t_{0}}^{s} k(\tau) d \tau\right] d s\right\} .
\end{aligned}
$$

Proof: Consider the function defined by the equality

$$
v(t)=\int_{t_{0}}^{t} b(s)\left[u(s)+\int_{t_{0}}^{s} k(\tau) u(\tau) d \tau\right] d s+\sum_{t_{0}<t_{k}<t} \beta_{k} u\left(t_{k}\right) .
$$


The function $v \in P C\left(\left[t_{0}, \infty\right), \mathbb{R}_{+}\right)$is nondecreasing and satisfies the inequalities

$$
u(t) \leq a(t)+v(t)
$$

and

$$
\begin{aligned}
v(t) & \leq \int_{t_{0}}^{t} b(s)\left[a(s)+\int_{t_{0}}^{s} k(\tau) a(\tau) d \tau\right] d s+\sum_{t_{0}<t_{k}<t} \beta_{k} a\left(t_{k}\right) \\
& +\int_{t_{0}}^{t} b(s)\left[v(s)+\int_{t_{0}}^{s} k(\tau) v(\tau) d \tau\right] \begin{array}{c}
d s+\sum_{t_{0}<t_{k}<t} \beta_{k} v\left(t_{k}\right) .
\end{array}
\end{aligned}
$$

From inequality (13) and Theorem 1 we obtain the inequality

$$
\begin{aligned}
v(t) & \leq\left\{\int_{t_{0}}^{t} b(s)\left[a(s)+\int_{t_{0}}^{s} k(\tau) a(\tau) d \tau\right] d s+\sum_{t_{0}<t_{k}<t} \beta_{k} a\left(t_{k}\right)\right\} \\
& \times \prod_{t_{0}<t_{k}<t}\left(1+\beta_{k}\right) \exp \left\{\int_{t_{0}}^{t} b(s)\left[1+\int_{t_{0}}^{s} k(\tau) d \tau\right] d s\right\}
\end{aligned}
$$

Thus, (10) follows from inequalities (12) and (14).

Corollary 1: Let the conditions of Theorem 3 hold for $a(t) \equiv a=$ const $\geq 0$.

Then, for $t \geq t_{0}$, the following inequality is valid:

$$
\begin{aligned}
& u(t) \leq a\left\{1+\int_{t_{0}}^{t} b(s)\left[1+\int_{t_{0}}^{s} k(\tau) d \tau\right] d s+\sum_{t_{0}<t_{k}<t} \beta_{k}\right\} \\
& \quad \times \prod_{t_{0}<t_{k}<t}\left(1+\beta_{k}\right) \exp \left\{\int_{t_{0}}^{t} b(s)\left[1+\int_{t_{0}}^{s} k(\tau) d \tau\right] d s\right\}
\end{aligned}
$$

\section{Application}

With the aid of the established inequalities we shall analyze the continuous dependence of the solutions of the initial value problem for impulsive integrodifferential equations on the initial data.

Consider the nonlinear impulsive integro-differential equation

$$
\dot{x}=f\left(t, x, \int_{t_{0}}^{t} k(t, s, x(s)) d s\right), \text { for } t \neq t_{k}
$$




$$
\left.\Delta x\right|_{t=t_{k}}=I_{k}\left(x\left(t_{k}\right)\right)
$$

with initial condition

$$
x\left(t_{0}\right)=x_{0}
$$

where $\left.\Delta x\right|_{t=t_{k}}=x\left(t_{k}+0\right)-x\left(t_{k}-0\right)$.

Theorem 4: Let the following conditions hold:

1. The function $f \in C\left(\left[t_{0}, \infty\right) \times \mathbb{R} \times \mathbb{R}, \mathbb{R}\right)$ and it satisfies the inequality

$\left|f\left(t, x_{1}, y_{1}\right)-f\left(t, x_{2}, y_{2}\right)\right| \leq g(t)\left|x_{1}-x_{2}\right|+h(t)\left|y_{1}-y_{2}\right|, x_{1}, x_{2}, y_{1}, y_{2} \in \mathbb{R}$

where $g, h \in C\left(\left[t_{0}, \infty\right), \mathbb{R}_{+}\right)$.

2. The function $k \in C\left(\left[t_{0}, \infty\right) \times\left[t_{0}, \infty\right) \times \mathbb{R}, \mathbb{R}\right)$ and it satisfies the inequality

$$
\left|k\left(t, s, x_{1}\right)-k\left(t, s, x_{2}\right)\right| \leq m(t, s)\left|x_{1}-x_{2}\right|, x_{1}, x_{2} \in \mathbb{R}
$$

where $m \in C\left(\left[t_{0}, \infty\right) \times\left[t_{0}, \infty\right), \mathbb{R}_{+}\right)$.

3. The functions $I_{k}(x): \mathbb{R} \rightarrow \mathbb{R}(k \in \mathbb{N})$ satisfy the inequality

$$
\left|I_{k}\left(x_{1}\right)-I_{k}\left(x_{2}\right)\right| \leq \beta_{k}\left|x_{1}-x_{2}\right|, x_{1}, x_{2} \in \mathbb{R}
$$

where $\beta_{k}=$ const $>0$.

4. For each point $x_{0} \in \mathbb{R}$, the initial value problem (15), (16), (17) has a solution $x\left(t ; t_{0}, x_{0}\right)$ for $t \geq t_{0}$.

Then, the solutions of equation (15), (16) depend continuously on the initial conditions, i.e., for any number $\epsilon>0$, there exists a number $\delta>0$ such that for $\left|x_{0}-y_{0}\right|<\delta$ the inequality

$$
\left|x\left(t ; t_{0}, x_{0}\right)-x\left(t ; t_{0}, y_{0}\right)\right|<\epsilon
$$

holds for $t \in\left[t_{0}, T\right], T=$ const $>t_{0}, T<\infty$.

Proof: Let $\epsilon>0$ be an arbitrary number. Consider the function $u(t)=$ $\left|x\left(t ; t_{0}, x_{0}\right)-x\left(t ; t_{0}, y_{0}\right)\right|$, which by the condition of Theorem 4 satisfies the inequality

$$
\begin{aligned}
& u(t) \leq\left|x_{0}-y_{0}\right| \\
& +\int_{t_{0}}^{t}\left[g(s) u(s)+h(s) \int_{t_{0}}^{s}\left|k\left(s, \tau, x\left(\tau ; t_{0}, x_{0}\right)\right)-k\left(s, \tau, x\left(\tau ; t_{0}, y_{0}\right)\right)\right| d \tau\right] \\
& \quad+\sum_{t_{0}<t_{k}<t} \beta_{k} u\left(t_{k}\right) \\
& \leq\left|x_{0}-y_{0}\right|+\int_{t_{0}}^{t} g(s) u(s) d s+\int_{t_{0}}^{t} h(s) m(s, \tau) u(\tau) d \tau d s+\sum_{t_{0}<t_{k}<t} \beta_{k} u\left(t_{k}\right) .
\end{aligned}
$$

From inequality (18), by Theorem 2 we obtain the inequality 


$$
u(t) \leq\left|x_{0}-y_{0}\right| \prod_{t_{0}<t_{k}<t}\left(1+\beta_{k}\right) \exp \left\{\int_{t_{0}}^{t} g(s) d s+\int_{t_{0}}^{t} h(s) m(s, \tau) d \tau d s\right\}
$$

We choose $\delta>0$ such that

$$
0<\delta<\epsilon\left\{\prod_{t_{0}<t_{k}<T}\left(1+\beta_{k}\right) \exp \left[\int_{t_{0}}^{T} g(s) d s+\int_{t_{0}}^{T} h(s) m(s, \tau) d \tau d s\right]\right\}^{-1} .
$$

Inequalities (19) and (20) yield the assertion of Theorem 4.

\section{Acknowledgement}

The present investigation was supported by the Bulgarian Ministry of Education, Science and Technologies under Grant MM-511.

\section{References}

[1] Bainov, D.D. and Simeonov, P.S., Integral Inequalities and Applications, Kluwer Academic Publishers, Dordrecht 1992.

[2] Simeonov, P.S. and Bainov, D.D., On an integral inequality for piecewise continuous functions, J. Math. Phys. Sci. 21:4 (1987), 315-323.

[3] Simeonov, P.S. and Bainov, D.D., Integral and differential inequalities for a class of piecewise continuous functions, Ann. Polon. Math. XLVIII (1988), 207216 (in Russian).

[4] Simeonov, P.S. and Bainov, D.D., Perturbation theorems for systems with impulse effect, Int. J. Systems Sci. 19:7 (1988), 1213-1223. 


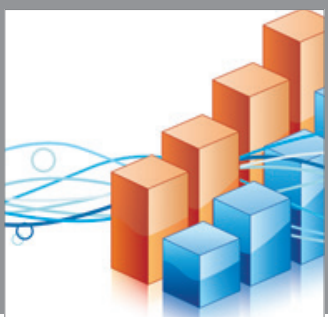

Advances in

Operations Research

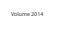

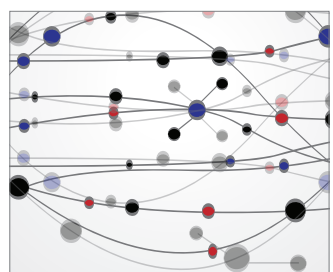

\section{The Scientific} World Journal
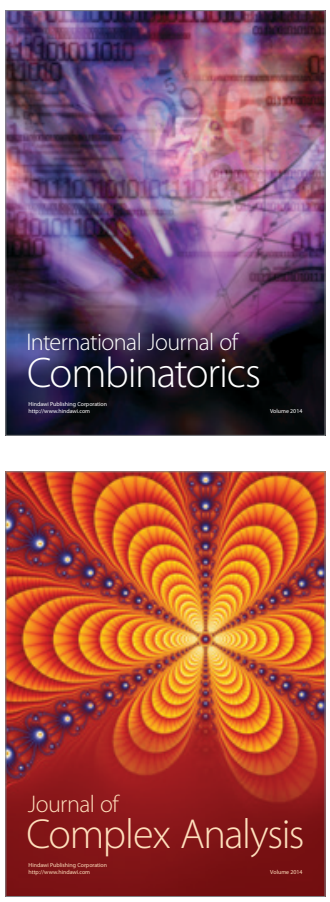

International Journal of

Mathematics and

Mathematical

Sciences
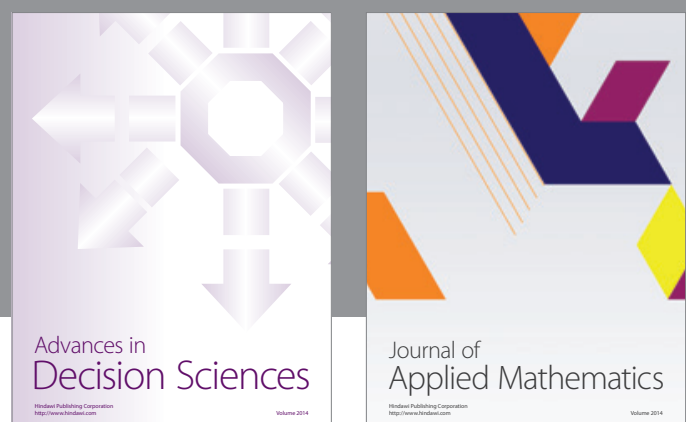

Journal of

Applied Mathematics
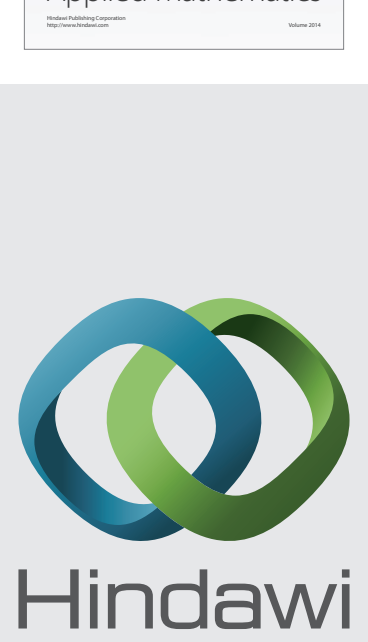

Submit your manuscripts at http://www.hindawi.com
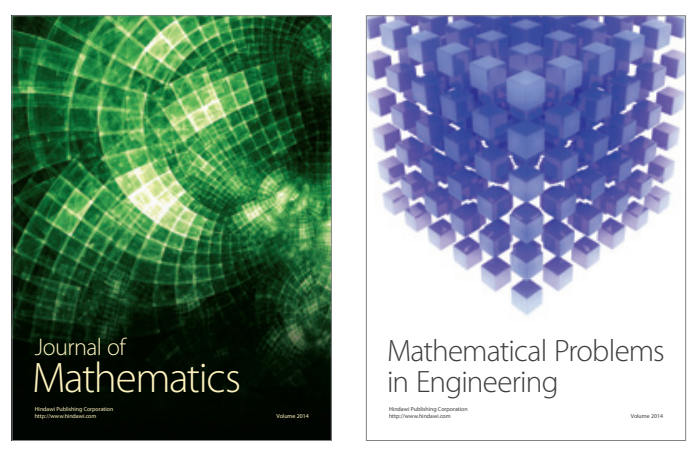

Mathematical Problems in Engineering
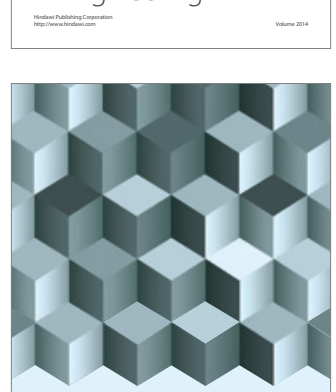

Journal of

Function Spaces
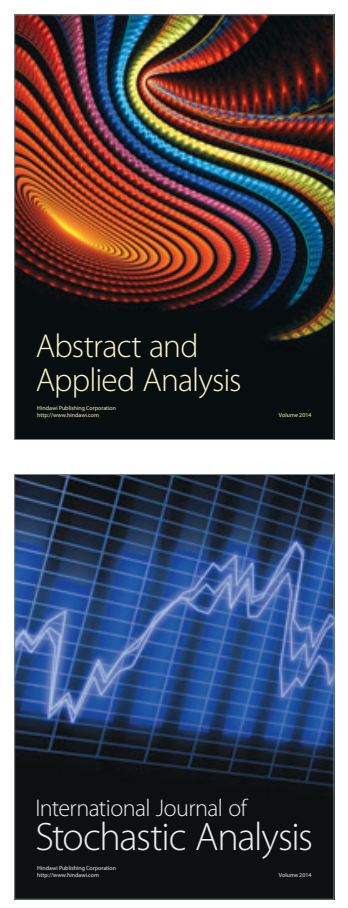

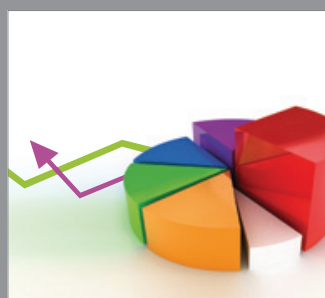

ournal of

Probability and Statistics

Promensencen
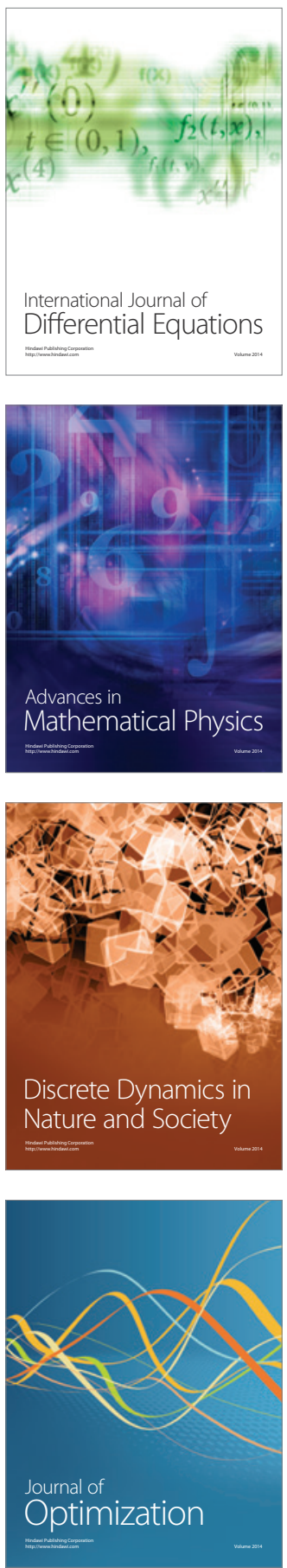